\title{
La paradoja del sentido del voto emitido por los fondos de pensiones de los sindicatos, en las juntas generales de accionistas de las sociedades cotizadas en los Estados Unidos
}

\author{
Iñigo Zavala \\ Universidad de Deusto
}

\begin{abstract}
Labor is prior to, and independent of, capital. Capital is only the fruit of labor, and could never have existed if labor had not first existed. Labor is the superior of capital, and deserves much better consideration.
\end{abstract}

Abraham Lincoln 1

Sumario: I. Introducción. II. Los Unions Pension Funds como Inversores Institucionales. III. Las Shareholders Proposals. IV. El cambio en el sistema de pensiones y el apoyo a la Shareholder Primacy. A) Del «Defined Benefit Plan» al «Defined Constribution Plan». B) El apoyo a la Shareholder Primacy. $\checkmark$. La nueva, e inimaginada, política de voto de los fondos de pensiones de los sindicatos en los Estados Unidos. A) Breve apunte histórico. B) Oposición a la misma. C) Potencial conflicto de intereses. VI. Conclusiones.

Resumen: La condición de accionistas, de los fondos de pensiones de los sindicatos estadounidenses, hace que en determinadas ocasiones, el ejercicio del voto en el seno de las Juntas Generales, no deje de ser paradójico. En efecto, a su cualidad de accionista, hay que unir - por supuesto- la de ser representantes de los trabajadores de la misma empresa. En algunas ocasiones esta dualidad puede generar conflictos de intereses.

Palabras clave: Fondos de Pensiones Sindicales, Propuestas de los accionistas, Shareholder Primacy, Inversores Institucionales, Sistema de pensiones, Constituencies.

1 LINCOLn, A.: Annual Message to Congress (december 3, 1861). En O’Connor, M.A.: «Organized Labor as Shareholder Activist: Building Coalitions to Promote Workers Capitalism». University of Richmond Law Review. 1997. Vol. 31,p. 1345. 
Abstract: The cast of the vote by the Union Pension Funds as shareholders activists, is sometimes paradoxical. This is due to the double condition of those funds, as shareholders and as representatives of labor. This twofold position can lead to some conflicts of interest.

Key words: Union Pension Funds, Shareholders Proposals, Institutional Investors, Shareholder Primacy, Constituencies, Pension System. 


\section{Introducción}

Tal y como ya hemos dicho en esta misma revista, en los Estados Unidos, de forma absolutamente mayoritaria, se ha impuesto en la doctrina, en la judicatura y en la opinión pública, el denominado Shareholder Primacy, o principio de que la sociedad debe ser gestionada, en beneficio de sus accionistas. Es decir, la dirección y administración de la sociedad deberán tener en cuenta, en primer lugar, los intereses de estos, y solo de forma secundaria o residual los de los otros constituencies de la misma; sobre todo los de los trabajadores, pero también los de los acreedores, proveedores, clientes y la comunidad en la que la compañía tiene sus establecimientos, oficinas o industria. Este principio, es el defendido de forma feroz por la mayoría de la amplia panoplia de fondos y planes de pensiones, compañías aseguradoras, sociedades de inversión y bancos de negocios que integran lo que se ha venido en denominar los Inversores Institucionales. Aunque, no es el objeto primordial de este trabajo, si que de forma tangencial, apuntaremos, como una de las causas de consolidación de esta doctrina fue precisamente, el cambio operado en el sistema de pensiones de los Estados Unidos, al final de la década de los 70 .

Este cambio, también está en el origen de la disyuntiva a la que se enfrentan los Fondos de Pensiones Sindicales en los Estados Unidos, en tanto que representantes de los trabajadores; y en tanto que accionistas de las sociedades en las que invierten los recursos de sus afiliados y simpatizantes. A este posible conflicto de intereses (o problema), dedicaremos la parte principal de nuestro trabajo.

Para ello, en el apartado I realizaremos una breve clasificación de los Inversores Institucionales, con especial mención a los Fondos de Pensiones Sindicales o Unions Pension Funds; en el II trataremos de explicar en qué consiste una propuesta de accionistas o shareholder proposal; en tanto que es el ariete elegido por los fondos sindicales para ejercitar su activismo accionarial. En el apartado III haremos una mención al cambio operado en el sistema de pensiones de los Estados Unidos, y las distintas consecuencias que el mismo ha deparado a los efectos que aquí nos ocupan. En cuarto lugar entraremos en el comentario de los posibles conflictos de interés que pueden surgir a estos fondos. Concluiremos, en el apartado V. 


\section{Los Union Pension Funds como Inversores Institucionales ${ }^{2}$}

El valor de las acciones gestionadas por los II.II se ha incrementado de forma sostenida, durante los últimos 60 años. En efecto, han pasado a representar del 7 u $8 \%$ del capital de las empresas cotizadas en los años 50; hasta el $67 \%$ en 2010. Este valor, es aún mayor en la grandes sociedades, ya que en 2009, los II.II tenían el $73 \%$ de las 1.000 mayores empresas de los Estados Unidos 3 . De estas cifras, y ajustando más al tema que nos ocupa en este trabajo, podemos concretar — según datos del Employee Benefit Research Institute- que los activos gestionados por planes o fondos de pensiones, vinculados con trabajadores eran del $0,8 \%$ en $1950 ; 4 \%$ en $1960 ; 9,4 \%$ en 1970 , $18,6 \%$ en 1980 y 22,9 \% en 1990. En 1998 la cifra había subido a $27,3 \%$ con una valoración de 3,5 trillones de dólares ${ }^{4}$.

Reflejando la importancia de los fondos de pensiones públicos, así como los de los Sindicatos, Peter Drucker ${ }^{5}$ popularizo la frase «pension fund socialism» justo después de la aprobación de la Employee Retirement Income Security Act (ERISA) ${ }^{6}$. Este concepto, captura la importancia mayúscula de la industria de los fondos de Pensiones en los estados unidos, y de los trabajadores como últimos beneficiarios ${ }^{7}$ de los mismos. Ahora bien, por razones que más tarde apuntaremos, la mayoría de los Fondos que integran esa «nebulosa» a la que denominamos «Inversores Institucionales», no realizan una labor activista en las juntas. Realmente, solo la ejercen los Public Pension Funds, y los que CAMARA denomina «Multilateral Investors» ${ }^{8}$.

2 Vid. CAMARA, K.A.D. "Classifying Institutional Investors» The Journal of Corporation Law. 2005. Winter. p.220. en la que realiza una clasificación simple y clara de los distintos tipos de fondos y entidades que conforman los llamados inversores institucionales en los Estados Unidos.

3 Ver en http://www.conference-board.org/publications/publicationdetail. cfm?publicationid=1872. así como el https://www.sec.gov/News/Speech/Detaild Speech/1365171515808. Última entrada 28 de diciembre de 2013. en la que el comisionado Luis A. Aguilar ofrece estos datos en la conferencia dada en la Georgia State University, el 19 de abril de 2013, bajo el título «Institutional Investrors: Power and Responsability»

4 Davis, R.B.: Democratizing Pension Funds. Toronto. Ed: Ubc Press. 2008. p. 3.

5 DruCKER, P.F.: The Unseen Revolution: How Pension Fund socialism came to America. New York. Ed: HarperCollins. 1976.

6 Vid. Employee Retirement Income Security Act (ERISA) en http://www.dol.gov/dold topic/health-plans/erisa.htm. Última entrada 7 de enero de 2014.

RoTH, M.: «Labor and Comparative Corporate Governance in Times of Pension Capitalism». Fordham Journal of Corporate \& Financial Law. 2013.Vol. XVIII, p. 754.

8 CAmara, K.A.D.: "Classifying Institutional...», op. cit., p. 239, en donde dice: «Multilateral investors have a variety of financial relationships with the firm. If the pay- 
Otra forma de clasificarlos, es establecer la división entre Fondos de Pensiones Públicos (que son aquellos que se nutren de las aportaciones de la Administración y que tienen como objeto garantizar las pensiones de los funcionarios públicos); y los Privados. Estos últimos los dividimos en Corporate Pension Funds o Plans (la mayoría) que están nutridos por las aportaciones de las empresas y que por lo tanto están gestionados por un órgano de administración participado mayoritariamente por representantes de las mismas; y en los denominados Union Pension Funds, que son los que canalizan los fondos de los sindicatos de trabajadores (tambien denominados Taft-Hartley Plans ${ }^{9}$ ). Aunque la Taft-Hartley Act, prohibe a las empresas realizar cualquier tipo de aportación a un sindicato ${ }^{10}$ (incluidos los Fondos o Planes de Pensiones de estos); realiza una excepción para aquellos Fondos en los que su órgano de administración o dirección, esté integrado, por el mismo número de representantes de la dirección de la empresa, y de los sindicatos (además de otras exigencias) ${ }^{11}$. Pero a pesar de la paritaria composición del órgano de gobierno del fondo, lo cierto es que los sindicatos, han tendido a dominar estos; de hecho es «...often very difficult to distingish between the pension fund and the union» ${ }^{12}$. La razón, tal y como más adelante veremos, radica en la formula de aportación al plan elegida. Si es la Defined Benefit, o la Defined Contribution.

En una dimensión distinta, se encuentran los Mutual Funds ${ }^{13}$, que recogen las portaciones tanto de particulares como de instituciones y otros fondos; es decir canalizan a su vez inversiones, tanto de fondos

offs associated with these relationships are different from those associated with equity ownership, these multilateral investors will sometimes not want to maximize shareholder value. The most popular legal response to multilateral investors has been to mandate separation of the parts of the multilateral investor dealing with each financial relationship».

9 Creados por la Labor Management Relations o Taft-Hartley Act de 1947 (en concreto por la Secc. 302). Ver en el National Labor Relations Board http://www.nlrb.gov, resources/national-labor-relations-act. Última entrada el 30 de diciembre de 2013.

10 Ibid.: "The Taft-Hartley Act forbids employers from making paymentsof any kind to a union, including union-run pension funds, but makes an exception...».

11 Ver en http://www.law.cornell.edu/uscode/text/29/186. El título 29, artículo 186 - Restriction on Financial Transactions-, apartado (c) exige que ademas: a) Los fondos deben ser gestionados en el exclusivo beneficio de los empleados y sus familias, b) Un acuerdo escrito en el que se pacte las bases, sobre las que el empleador realizará las aportaciones, c) el nombramiento de un árbitro imparcial que deshará los empates entre las partes,d) una auditoría anual y e)limitación de los rendimientos del fondo a atender determinadas contingencias (pensiones, seguros de vida y salud, becas, etc.).

12 BlodgetT, R.: «Union Pension Fund Asset Management», en Abuse on Wall Street: Conflicts of Interest on the Securities Markets. New York. Ed: Preager.1980, p. 327.

13 Vid. Camara, K.A.D.: «Classifying Institutional...», op. cit., p. 229. 
públicos como privados. Este tipo de fondos, a su vez, admiten estructuras de propiedad muy distintas. La más extendida es aquella, en la que se contrata con una gestora independiente, que, contra una remuneración consistente en un \% de los beneficios, gestiona el fondo y lo administra. Estas gestoras son sociedades mercantiles, con sus propios accionistas y que, lógicamente, buscan su propio beneficio. Existen por el contrario otros Mutual Funds (como por ejemplo en gigante Vanguard $^{14}$ ) que es gestionado por personal propio, no contratando terceras compañías ${ }^{15}$.

Tal y como nos dicen DEL GUERCIO, D. y WOIDTKE, T. ${ }^{16}$, tanto los Union Pension Funds (o Labor Unions Pension Funds, como también son denominados por estos autores) y los Public Pension Funds ${ }^{17}$ (aquellos que recogen las aportaciones de empleados públicos y funcionarios), se encuentran entre los mayores activistas accionariales. Según estos autores, y citando a Renneboog and Szilagyi ${ }^{18}$, el 38\% de las propuesta de accionistas, realizadas al amparo de la Rule 14a-8, que luego comentaremos, en el periodo 1996 a 2005; así como el 41\% de las propuestas de 2010, según la Annual Corporate Governance Review, fueron realizadas por estos dos clases de fondos. No podemos dejar de citar los temidos, y también prolíficos Hedge Funds' ${ }^{19}$; que no obstante nos limitaremos a nombrar, para evitar que sus muchas particularida-

14 Vid. Vanguard Funds en https://investor.vanguard.com/corporate-portal. Última entrada 18 de enero de 2014. Este Fondo, precisamente, vende como elementos diferenciadores de su filosofía, el que al ser los gestores del fondo «de la casa», pueden aplicar unas tarifas hasta un $« 83 \%$ lower fees» y además mirar solo en el beneficio de sus partícipes.

15 Vid. a este respecto Bogle, J.C.: The Class of the Cultures. Investment v. speculation. Hoboken. New Jersey. Ed: John Wiley \& Sons Inc. 2012, p. 127. Donde podemos leer: "In contrast to this traditional organization structure -in which the funds are essentially corporate shells - is the mutual structure one in which the funds actually own the management company, which then operates on an at - costs basis-. Here, the officers and directors of the management company, creating substantial advantages for the funds shareholders ...».

16 Ver su trabajo «Do the interest of Public Pension Fund and...», op. cit.

17 GHILARDucCl, T.; HAWLEY, J. y Williams, A.: «Labour Paradoxical Interest and the Evolution of Corporate Governance». Journal of Law and Society. 1997. Vol. 24, p. 26. En esta fecha, los autores estiman que el $35 \%$ de las acciones de las sociedades cotizadas, eran propiedad de fondos de pensiones de trabajadores (sindicados o no).

18 Renneboog, L. y SzILagvi, P.G.: "The Role of Shareholders Proposals in Corporate Governance». Journal of Corporate Finance. 2010. Vol. 17, p. 167.

19 Vid. Brav, A. et al.: "Hedge Fund Activism, Corporate Governance and Firm Performance». The Journal of Finance. 2008. Vol. 63. n. ${ }^{\circ}$ 4, p. 1729; y KAHAN, M. y Rock, E.B.: «Hedge Funds in Corporate Governance and Corporate Control». University of Pennsylvania Law Review. 2007, Vol 155. n. ${ }^{\circ}$.5, p. 1021. 
des (principalmente al carecer casi totalmente de regulación legal) nos distraigan de nuestro objetivo principal.

Pero este activismo ha sido, sin duda, controvertido. En efecto ha habido bastante especulación sobre cuáles son los verdaderos motivos que impulsan el mismo. Así, muchos opinan que existe una inspiración política en los empleados de estos fondos, más preocupados en generar beneficios privados y publicidad para futuras campañas políticas (estos fondos tradicionalmente están vinculados al partido demócrata) que en maximizar la riqueza de los accionistas ${ }^{20}$. Otros ${ }^{21}$ entienden que utilizan este activismo como plataforma desde la que obtener beneficios para los trabajadores afiliados al sindicato. Una visión alternativa, defiende que estos son los únicos inversores que tienen incentivos para fiscalizar activamente a la dirección o management de la sociedad. En efecto, otro tipo de inversores institucionales en los Estados Unidos, son las compañías de seguros, los bancos de inversión y, sobre todo, los Mutual Funds. Y ninguno de ellos entrara en confrontación con la dirección de una empresa a la que tiene por cliente, o a la que quiere acceder $^{22}$. Y aunque, existen muchos estudios ${ }^{23}$ que tratan de demos-

20 Ver, entre otros, Romano, R.: «Public Pension Fund Activism in Corporate Governance Reconsidered», Columbia Law Review. 1993. Vol. 93, p. 795.

21 En este sentido ver ANABTAWI, I. y STOUT, L.: «Fiduciary Duties for Activist Shareholders». Stanford Law Review. 2007. Vol. 60, p. 1255; y BAINBRIDGE, S.: «The Case for Limited Shareholders Voting Rights» UCLA Law Review. Vol. 53, p. 601.

22 AsHRAF, R. et al.: "Conflicts of interest and mutual fund proxy voting: Evidence from shareholder proposals on executive compensation». Journal of Financial and Quantitative Analysis. 2012. Vol. 47. Issue 3, p. 567.

23 AgRAWAL, A.K.: «Corporate Governance Objectives of Labor Union Shareholders: Evidence from proxy Voting». Ver en la página web de la New York University, http:// archive.nyu.edu/bitstream/2451/27848/2/wpa08006.pdf. Última entrada 6 de enero de 2014. En donde realiza un repaso por los diferentes estudios a este respecto realizados, señalando que "First, the study provides unique empirical evidence that the preferences of labor union shareholders may reflect objectives other than equity value maximization. While there is debate in the academic literature and business press that labor unions use their pension funds to pursue worker interests, there is little data to support the numerous viewpoints. The findings in this paper support theories postulated by Romano (2001) and Schwab and Thomas (1998). Second, this paper contributes to the corporate governance literature on proxy voting. Davis and Kim (2007), Matvos and Ostrovsky (2007), and Rothberg and Lilien (2005) utilize recent, publicly disclosed data to explore various voting incentives facing mutual fund managers. In contrast, this paper utilizes data on labor union pension fund proxy votes to study the governance objectives of union shareholders. Third, this work contributes to a burgeoning literature on the role of employee stakeholders on corporate decisions and outcomes (Atannasov and Kim 2008, Chen, Kacperzyck, Molina 2008). This study suggests that union shareholder activists look towards corporate governance mechanisms as a means of furthering the goals of unionized employees. Finally, the data shed light onto policy discussions con- 
trar una u otra posición, lo cierto es que es muy difícil de demostrar cuál es la verdadera razón que anima a estos fondos a votar en uno u otro sentido. Más adelante volveremos sobre este tema, pero esta vez, centrándonos en los posibles conflictos de intereses que pueden surgir en el seno de los Unions Pension Funds.

cerning potential governance reforms. One contentious issue currently facing the SEC is whether shareholders should be given greater powers over corporate affairs through increased access to annual director election ballots (see Bebchuk (2005), Harris and Raviv (2007), and Bainbridge (2006) for further discussion). Labor union activists such as the AFL-CIO generally favor greater shareholder powers as a means of improving the financial performance of firms. However, other groups such as the Business Roundtable argue that greater shareholder powers would ironically empower special-interest investors to advance their agendas at the expense of shareholder value (McKinell 2003). The underlying question in this debate is whether shareholders have disparate preferences to begin with».

Asimismo, citamos por su interés, PreVost, A.K.; RAO, R.P. y WILLIAMS, M.A.: «Shareholder Activist: Champions or Detractors» ver en http://papers.ssrn.com/sol3/papers. cfm?abstract_id=1119328. Última entrada 15 de enero de 2014, en donde, en su p. 22, nos dicen «We find that the initial market reaction to labor union sponsored proposals is insignificant in the overall sample. However we observe a significant positive reaction surrounding proposals at unionized target firms for proposals that achieve majority-vote status. Viewed collectively, our study results do not support the incentive conflict hypothesis that labor unions use shareholders proposals to extract even greater gains for the employee, their primary constituency. On the contrary, our study implies that unions may be unique in their ability to spur changes in governance characteristics that lead to shareholder wealth improvement, and the ability to produce this changes is related to union presence at targets as well as overall shareholders support for their proposals». Asimismo, THOMAS, R.S. y MARTIN, K.J.: "Should Labor be allowed to Make Shareholders Proposals» Washington Law Review. 1998. Vol. 73. n. ${ }^{\circ}$ 1, en su p. 73, nos dicen "We found that labor Union proposals received more votes that did proposals from private institutions and individuals, even after controlling for the type of proposal and ownership structure. These higher vote totals for labor proposals were comparable to those received by public institutions. We interpret these results to suggest that any conflict of interest that may arise between labor unions and other shareholders may not be as great as feared. Proposals by labor unions are not treated harshly by shareholders in general. Rather, they appear to be viewed by Shareholders as no different from proposals by other sponsors». Por el contrario, sí que entienden que la actividad de los Labor Unions crea un claro perjucio al valor de la sociedad tanto FALEYE, O.; MeHrotra, V. y MORCK, R.: "When labor has a Voice in Corporate Governance» Journal of Financial and Quantitative Analysis. 2006. Vol. 41. Issue 3, p. 521, en donde concluyen "Our empirical findings cast a serious doubt on the simple premise that labor equity participation causes a convergence of interest between workers and shareholders»; y en el mismo sentido LARCKER, D.F. y TAYAN, B.: "Union Activism: Do Union Pension Funds Act Solely in the Interest of Beneficiaries? Stanford Closer Look Series. 11 de diciembre de 2012. 


\section{Las Shareholders Proposals}

Antes de entrar en el análisis y explicación de su régimen jurídico, debemos adelantar que estas Shareholder Proposals son el vehículo o herramienta preferido por los Fondos de Pensiones de los Sindicatos (en cuanto que accionistas), para tratar de influir en la dirección de las empresas.

Las Sharerholders Proposals están reguladas en la Secc. 14a-824 de la Securities Exchange Act de de 193425. Aunque el derecho de sociedades es una materia competencia de los Estados Federados, la representación en la Juntas Generales de las sociedades mercantiles ha sido regulada por una ley Federal. En efecto, las distancias en un país-continente, como es los Estados Unidos de América, hicieron que el legislador Federal entendiese que era necesaria una única norma que regulase la representación en las juntas, para que todos los ciudadanos estuviesen obligados por una única pauta o criterio al ejercitar este derecho; que caso contrario hubiese quedado sometido a las diferentes legislaciones de cada uno de los Estados Federados. Son por tanto, principalmente las grandes distancias; la cultura inversora de aquél país (en el que en la mayoría de las sociedades cotizadas el número de accionistas representados es siempre mucho mayor que el de presentes en la reunión ${ }^{26}$ ) y la utilización de medios interestatales (principalmente Correos) ${ }^{27}$ para el ejercicio del voto, lo que hizo que se regulara la representación en la Secc. $14^{28}$ de la antes mencionada Act.

Las shareholder proposals fueron concebidas, inicialmente, como un medio de comunicación entre los accionistas y la dirección de la

24 Vid en http://www.sec.gov/rules/final/34-40018.htm. Última entrada 28 de diciembre de 2013.

25 Vid en http://www.sec.gov/about/laws/sea34.pdf, última modificación 19 de agosto de 2012. Ultima entrada 28 de diciembre de 2013.

26 Yermack, D.: «Shareholder Voting and Corporate Governance». Annual Review of Financial Economics. 2010. Vol. 2, p. 103. En donde afirma, refiriéndose a la forma en la que se ejercita el voto en las Juntas de accionistas, que "Nearly all shareholders vote by proxy, sending in votes by mail or Internet rather than attending meetings to vote in person». http://papers.ssrn.com/sol3/papers.cfm?abstract_id=1523562, p. 5. Última entrada 30 de diciembre de 2013.

27 Gevurtz, F.A.: Corporation Law. Second Edition. Minnesota. Ed: Thompson Reuters. 2010, p. 245.

28 Cox, J.D.; Hillman, R.W. y Lagenvoort, D.C.: Securities Regulation. Selected Statutes, Rules and Forms. Frederick. Maryland. Ed: Wolters Kluwer. 2012. p. 519. En este libro se da una práctica visión de lo que es una Shareholder Proposal. 
compañía ${ }^{29}$. Aunque no podemos detenernos — desgraciadamenteen su azarosa existencia, de forma esquemática diremos que desde el año 34 hasta la década de los 60, la Securities and Exchange Commission realizo una labor de rebaja de su contenido y finalidad inicial, hasta que su ejercicio se convirtió en una cuestión testimonial ${ }^{30}$. Solo después de esa década, y tras la el auge en los 70 de movimientos sociales, religiosos, y de defensa de los derechos humanos, hicieron que de nuevo la SEC, haciéndose eco de esta nueva sensibilidad social, modificase su regulación para esta vez ampliar, las posibilidades de su ejercicio. Con la denominada «primavera de los accionistas» auspiciada, por la irrupción desde los años 80 de los Inversores Institucionales en la realidad financiera estadounidense, el ejercicio de este derecho está viviendo, de nuevo, su época dorada.

¿Qué es una Shareholder Proposa/? ${ }^{31}$ Es la recomendación o requerimiento $^{32}$ para que la compañía, o su Consejo de Administración, adopten la medida que un accionista propone, a la Junta General. En primer lugar, tenemos que destacar que no es, por lo tanto, vinculante. En efecto, aunque la propuesta obtenga una mayoría de los votos, el órgano de administración, puede hacer caso omiso de la misma ${ }^{33}$. No obstante, lógicamente, esta decisión suele tener importantes consecuencias para el Consejo, ya que al no cumplir con un claro mandato de sus accionistas, vera complicarse sobremanera sus posibilidades de reelección. Atendiendo al grado de activismo de los autores de la propuesta que hubiere obtenido apoyo mayoritario en la Junta, la compañía puede ser además objeto de una campaña de prensa - muy normal en EEUUque perjudique la reputación profesional de sus consejeros ${ }^{34}$. Y en se-

29 Tusk, D.: "Shareholders as Proxies: The Contours of Shareholder Democracy». Washington \& Lee Law Review. Vol. 63. 2006,.p. 1546.

30 Vid. Seligman, J.: The transformation of Wall Street. 3. ${ }^{a}$ edición. New York. Ed: Aspen Publishers. 2003; especialmente pp. 270 y ss.

31 Cox, J.D.; Hillman, R.W. y LAGenvoort, D.C.: "Securities Regulation. Selected...», op. cit., p. 539

32 La norma, literalmente dice «recommendation or requirement».

33 A diferencia de las shareholder proposals, las propuestas de acuerdo justificadas previstas en el artículo 519 de la Ley de Sociedades de Capital, serán de obligatorio cumplimiento para el consejo, en el caso de aprobarse en la Junta. Este artículo de la Ley, que fue incorporado a la misma en virtud de lo dispuesto en la Directiva 2007/36/ CE del Parlamento Europeo y del Consejo de 11 de Julio, se encuentra en el Título XIV «Sociedades Anónimas Cotizadas».

34 Vid. Artículo de 12 de abril de 2013, en la revista Forbes, en el que se hace eco del activismo del omnipresente y poderosísimo inversor Carl Icahn, que ha capitaneado alguna de las campañas de prensa más sonadas en contra de los consejos de administración de importantísimas sociedades de aquél país. http://www.forbes.com/sites/nathanvardi/ 2013/12/04/carl-icahn-is-wall-streets-person-of-the-year-and-going-after-appled. 
gundo que, tal y como veremos en siguientes párrafos, no es posible someter cualquier tipo de materia o asunto a la votación de la Junta. Así es, lo que afecta directamente a la gestión y administración de la sociedad, es competencia exclusiva de la dirección; ya que sería inviable el gobierno de una compañía de forma asamblearia o a través de referéndums entre sus accionistas.

Una vez la propuesta es aprobada por la sociedad —cosa a la que, como veremos, se puede oponer- esta tendrá que incluirla en el orden del día de la junta, y remitir a todos los accionistas, el documento justificativo de la misma que elaboren los autores de la propuesta.

¿Quién puede presentar una Shareholder Proposal? ${ }^{35}$ Aquellos accionistas que con un año de antelación, a la remisión de la propuesta a la compañía, hayan tenido invertidos -ininterrumpidamente- al menos 2.000 dólares en acciones de la compañía, ó sean propietarios del $1 \%$ del capital. Tendrá que obligarse a mantener esta inversión, hasta la celebración de la Junta. Solo se puede realizar una propuesta por Junta. Así mismo se limita su extensión, ya que la misma, así como los documentos que la justifiquen, no podrán exceder de 500 palabras $^{36}$.

¿Con qué antelación se debe presentar? Aquí rigen una serie de peculiaridades del derecho de sociedades estadounidense, en las que no podemos entrar. A los efectos que en este trabajo nos ocupan, baste decir que la propuesta, deberá estar en el domicilio social de la compañía, al menos con 120 días de antelación al día que la compañía envío la documentación sobre la junta (company's proxy statement) el año anterior. Si fuera una Junta Extraordinaria el limite es «...the deadline is a reasonable time before the company begins to print and e-mail its proxy materials».

Una vez recibida la propuesta, la sociedad, si entiende que la misma se ajusta a derecho, la incluirá en el orden del día, en cuyo caso el proponente o su representante legal, tendrá la obligación ${ }^{37}$ de asistir a la Junta para defender la misma ${ }^{38}$. El que la incorpore, no quiere decir que la dirección la apoye. De hecho la ley la autoriza a enviar a los accionistas (junto con el orden del día, la propuesta realizada y, en su caso, la justificación de la misma), un documento en el que la com-

35 Cox, J.D.; Hillman, R.W. y LAGENVOORT, D.C.: «Securities Regulation. Selected Statutes...», op. cit., p. 539.

36 Ibid., p. 540.

37 Ibid., p. 541.

38 Existen una serie de normas a este respecto, cuando la junta se puede celebrar «via electronic media» en las que no es necesaria la presencia física de ningún accionista. 
pañía solicite el voto en contra y argumente el mismo. Para el caso de que el proponente, entienda que la sociedad, en la oposición a su propuesta, realiza manifestaciones falsas o erróneas podrá dirigirse a la SEC con un escrito en donde trate de demostrar las falsedades o errores cometidos por la sociedad. Finalmente la SEC decidirá al respecto.

Pero la compañía puede oponerse a incluir la propuesta en el orden del día de la Junta, cuando entienda que la misma incurre en alguna de las 13 prohibiciones señaladas en el Secc. $14 a-8^{39}$ y que seguidamente pasamos a exponer: a) Cuando la misma no puede ser presentada como propuesta de accionistas, de acuerdo con la Ley de sociedades del Estado, en el que la compañía tiene su domicilio social; b) Si la propuesta, de aprobarse e implementarse, hiciese a la compañía infringir alguna Ley; c) Si la misma es contraria a la regulación, que del derechos de representación de los accionistas, realiza la SEC en la Secc. 14a-9 de la Securities Exchandge Act; d) Cuando la propuesta tenga como objetivo una reclamación personal contra la sociedad o un directivo, o se realice en interés individual del proponente; e) Que la misma se refiera a operaciones que signifiquen menos del $5 \%$ de los activos de la compañía al cierre del ejercicio económico más reciente; o menos que el $5 \%$ de sus ingresos netos o ventas brutas al cierre del último ejercicio; y que además no estén significativamente relacionada con el negocio de la compañía; f) Si la compañía no tuviera el poder o autoridad para implementar la propuesta; g) Si la propuesta se refiere a una materia relacionada con la gestión ordinaria de sus negocios; h) Si hace referencia a la elección de miembros del Consejo de Administración u otro órgano de administración de la misma ${ }^{40}$; i) Si la propuesta está en contradicción con uno de los puntos del orden del día propuesto por la dirección de la sociedad; j) Si la propuesta estuviera ya "substantially» implementada por la sociedad; k) Si la misma duplica "substantially» otra propuesta solicitada por otro accionista, que ya estaba incorporada al orden del día; I) Si la misma es similar a otra propuesta presentada, dentro de los 3 años anteriores y no hubiera obtenido un número de votos determinado (del 3\% al 10\% dependiendo del número de veces presentada) y m) Si la propuesta hace referencia al reparto de dividendos ${ }^{41}$.

39 Cox, J.D.; HILLMAN, R.W. y LAgenvoort, D.C.: «Securities Regulation. Selected Statutes...», op. cit., p. 541.

40 A este respecto existe un procedimiento especial en la Secc. 14a-11. Ver también GEVURTZ, F.A.: «Corporation Law». op. cit., p. 252.

41 En este caso, al igual que la g); la limitación tiene su origen, en la norma presente en todas las leyes de sociedades de todos los Estados Federados, que afirma que la di- 
Si la sociedad, entiende que la propuesta incurre en alguna/s de ellas deberá comunicarlo a la SEC y al accionista proponente, antes de los 80 días anteriores al plazo que tiene la compañía para remitir a la SEC, la información que enviará a sus accionistas con toda la documentación necesaria para conocer los distintos puntos del orden del día, así como la indispensable para poder emitir los votos de forma informada y en su caso otorgar la representación en favor de otra persona.

El accionista podrá, a su vez, remitir información a la SEC en la que oponga sus argumentos a los empleados por la compañía para negarse a incorporar la propuesta. Finalmente será la SEC, la que decida. Cuando la Comisión ratifica la decisión de la sociedad de no incluir la propuesta, esta se denomina «no-action letters ${ }^{42}$ ». La misma puede ser objeto de revisión ante la jurisdicción ordinaria43.

Finalizaremos este apartado, dando los principales datos de la «proxy season» de 2013, según estudio publicado el 11 de enero de 2014 por la consultora Gibson Dunn ${ }^{44}$. Según este informe, se presen-

rección y gestión de los negocios sociales reside en el órgano de administración. Ver por todos la Secc. 141(a) del Delaware Corporate Code, en donde se nos dice «The business and affairs of every corporation organized under this chapter shall be managed by or under the direction of a board of directors".

42 VAN DER ZWAN, N.: "The Making of Shared Capitalism: Business, Labor and Corporate Accountability in the Late Twenty Century». Paper presentado en el Workshop for the Study of Employee Ownership, Profit-sharing and Broad-Based Stock Options; Rutgers University, New Brunswick, New Jersey, 24 y 25 de febrero de 2011. Ver en el enlace http://smlr.rutgers.edu/2011-making-of-shared-capitalism-business-labor-andcorporate-accountability-natascha-van-der-zwan. Última entrada 30 de diciembre de 2013. Estas comunicaciones, reciben el nombre de «no action letters»; ya que la división de "Corporate Finance» (que es la encargada de contestar a la no inclusión de una una propuesta de los accionistas); para el caso de que encuentre la mencionada exclusión ajustada a derecho, contestará: "The Division will not recommend enforcement action to the Commision if the Company omits the proposal from its proxy materials».

43 En base a los dispuesto en la Rule 14a-4, cabe a si mismo presentar propuestas relativas a los estatutos de la sociedad, el mismo día en que se celebra la Junta (son las denominadas «flor resolutions»). Debido a que, en este caso, los proxies, (o información sobre la Junta y el orden del día) ya han sido enviados a los accionistas, y estos ya han ejercido su derecho de voto, a través del instituto de la representación; la dirección de la empresa (que es en favor de quien mayoritariamente se otorga la representación) podrá votar con libertad sobre ese nuevo punto del orden del día (insistimos no incorporado al enviado a los accionistas). Por lo que si la propuesta es contraria a los intereses de la dirección de la sociedad, las posibilidades de éxito son mínimas. Esta situación conlleva, además, otros problemas, en los que no podemos detenernos. Ver en ScHWAB, S.T. y THOMAS, R.S.: «Realigning Corporate Governance: Shareholder Activism by Labor Unions». Michigan Law Review. 1998. Vol. 96, p. 1066.

$44 \mathrm{Vid}$. Informe completo en http://www.gibsondunn.com/publications/pages/ Shareholder-Proposal-Developments-2013-Proxy-Season.aspx. Última entrada 16 de enero de 2014. 
taron 820 propuestas frente a las 739 del año anterior. El tipo de petición más solicitada, fue la que tenía como objetivo, limitar o pedir información sobre las contribuciones que, en su caso, la empresa hubiera realizado a algún tipo de campaña política (115); Desclasificación de los consejos de administración, en el sentido que sus todos sus miembros sean elegidos a la vez, y por periodos de tiempo no superiores a tres años (79); Prohibir la concurrencia en la misma persona del cargo de Presidente del Consejo y CEO de la sociedad (70); Eliminación de mayorías reforzadas para la elección de consejeros (48). La media de votos obtenidos por las propuestas fue del $34,4 \%$; y solo el $19 \%$ de las mismas fue capaz de concitar una mayoría de votos.

\section{El cambio en el sistema de pensiones y el apoyo a la Shareholder Primacy}

\section{A) Del «Defined Benefit» al «Defined Constribution» Plan}

Ha sido señalada por la doctrina, como una de las causas que precipitaron el activismo de los Inversores Institucionales, el cambio legal operado en el sistema de pensiones estadounidense ${ }^{45}$, en la década de los 70. Así es, hasta entonces los Inversores Institucionales representaban apenas un $20 \%$ de la inversión en la Bolsa de aquél país. Eran además unos inversores cómodos, que rara vez utilizaban sus votos en las juntas generales para contradecir las propuestas realizadas desde la dirección de la compañía.

Aunque tras la «New Deal», se creó en los Estados Unidos un sistema nacional de Seguridad Social; diversas razones (en especial una inflación que se comía las aportaciones de los trabajadores) hicieron que los sindicatos buscaran un complemento e incluso un sustituto a este régimen público ${ }^{46}$.

El sistema de pensiones privado de los trabajadores, ha sido construido - fundamentalmente- sobre dos instituciones el Defined Benefit Plan y el Defined Contribution Plan. El primero de ellos (DB) es el plan que, hasta final de los 70 o principios de los 80 fue utilizado de forma mayoritaria por los empresarios-empleadores y por los trabajadores-empleados como fórmula que mejor se adecuaba a la situación del

45 Zelinsky, E.A.: «The Defined Contribution Paradigm». Yale Law Journal. 2004. Vol. 114, p. 451.

46 Gelter, M.: "The Pension System and the Rise of Shareholder Primacy». Seton Hall Law Review. 2013. Vol. 43, n. ${ }^{\circ} 3$, p. 918. 
mercado, y al marco legislativo (especialmente laboral y fiscal) vigente en aquellos años. En síntesis, en este tipo de plan, el empleador garantiza a los empleados una pensión determinada para cuando estos se jubilen. Será el empleador el que año tras año tendrá que ir realizando aportaciones al plan, para atender las obligaciones contraídas con sus trabajadores. En este caso una diligente gestión del fondo puede llegar a ahorrar mucho dinero al empresario. Por el contrario una «pobre» gestión del mismo avocará al empleador a tener que realizar aportaciones complementarias. Por ello, estos fondos, son administrados y gestionados de forma directa por la o las sociedades que realizan las aportaciones a estos fondos ${ }^{47}$.

En el caso de los Defined Contribution Plans ${ }^{48}$, (DC) el empleador o empresario, simplemente se obliga a realizar una aportación determinada al plan, con una periodicidad pactada (normalmente anualmente). El importe de esta aportación es uno de los temas estrella en las negociaciones colectivas de aquél país. La obligación del empresario llega hasta aquí, es decir, realizar la aportación consensuada. El cómo se gestiona este fondo -que rentabilidades son capaces de obtener sus gestores, etc. - en cierta forma "le es indiferente». Insistimos: el empresario ya ha cumplido. A los que no les es en absoluto indiferente es a los trabajadores. En efecto, ellos saben que una acertada gestión del plan, redundará en una mejora de sus percepciones. Por el contrario una deficiente o escasa rentabilidad significaría una reducción de su disponible en el futuro. Por ello, en este segundo caso, y aunque la Taft-Hartley Act exige que estos planes sean administrados de forma paritaria entre la empresa y los trabajadores; de hecho, son gestionados por estos últimos que son los que realmente se juegan la cuantía de las percepciones de su futura jubilación ${ }^{49}$.

Un aserie de quiebras en los años 70, que dejaron a los trabajadores, no solo sin trabajo, si no también sin plan de pensiones (los empresarios no habían dotado los mismos, tal y como con ellos había sido pactado), hizo que el gobierno tomara cartas en el asunto y, entre otras medidas aprobase la Employee Retirement Income Security Act $\left(\right.$ ERISA) ${ }^{50}$. En esta nueva Ley, entre otras cuestiones, se reforzaban las exigencias formales y materiales para crear un DB Plan, y además se en-

47 Ibid., p 928.

48 Ibid., p. 930.

49 Vid. Una crítica a esta norma en: Fogdall, S.: «Exclusive Union Control of Pension Funds: Taft - Hartley's III Considered Prohibition». University of Pennsylvania Journal of Labor and Employment Law. 2001. Vol. 4, p. 215.

50 Vid. Supra nota 6. 
durecía el régimen de responsabilidad de los empresarios ante cualquier incumplimiento relacionado con esta materia. Aunque la nueva normativa tenía como objetivo la defensa de los intereses de trabajadores y pensionistas, las nuevas exigencias hicieron a los DB Plans poco atractivos y costosos para los empleadores ${ }^{51}$. Una modificación en la Ley del Impuesto sobre la Renta ${ }^{52}$, que favorecía ligeramente a los DC Plans, sobre los DB Plans, hizo el resto. Como resumen de esta evolución señalar que en 1975 existían 20.035 DB Plans y 8.587 DC Plans de más 100 partícipes. En 2006, ya se había modificado totalmente la situación: 11.369 DB Plans y 70.125 DC Plans, de más de 100 partícipes $^{53}$.

\section{B) El apoyo a la Shareholder Primacy}

Tal y como ya hemos adelantado, y antes de entrar a exponer el conflicto de intereses en el que pueden incurrir los fondos de pensiones sindicales; haremos una rápida mención - por considerarlo, así mismo, del máximo interés - a la influencia que la actuación de Union Pension Funds, y los Public Pension Funds, han tenido en la consolidación de la Shareholder Primacy.

Con anterioridad a 1980, muy poco dinero de las pensiones fue invertido en acciones. Entre otras razones porque la legislación que regulaba los sistemas de pensiones de los Estados Federados solo permitía este tipo de inversión de forma muy limitada. Por ejemplo, hasta 1984, cuando se aprobó una enmienda a la constitución del Estado de California, CALPERS 54 , sólo podía invertir el 25\% de sus activos en acciones. Pero desde los 90, con el auge del movimiento desregulador, e imponiéndose el capital variable como la inversión más rentable, los Planes de pensiones empezaron a invertir fuertemente en acciones. Es decir, los fondos de pensiones públicos (aquello ligados a los funcionarios de la administración de los distintos Estados) entraron en el mercado de capitales, ya que los privados obtenían claramente mejores

51 Gelter, M.: «The Pension System and the Rise of Shareholder...», op. cit., p. 925.

52 Epígrafe $401(\mathrm{k})$ of the Internal Revenue Code.

53 Vid. En la pág. Web del Departament of Labor. Employees Benefits Security Administration. http://www.dol.gov/ebsa/pdf/1975-2006historicaltables.pdf. Última entrada 14 de enero de 2014.

54 Vid. California Public Employees Retirement System, más conocido como CALPERS. Es el fondo de Pensiones de empleados públicos más grande d los Estados Unidos. Ha destacado por su activismo, y por ser un referente a nivel mundial en la lucha por los derechos de los accionistas. http://www.calpers.ca.govd. Última entrada 14 de enero de 2014 
resultados que ellos ${ }^{55}$. El resultado, fue la irrupción en el escenario financiero, de una serie de fondos cuyos participes eran trabajadores en activo, que trataban de: a) Rentabilizar sus ahorros, a través de distintas modalidades de planes, y b) Que les garantizase una pensión digna cuando llagase su jubilación.

Fruto de los cambios legislativos señalados, podemos señalar dos consecuencias en el entendimiento del vínculo entre los trabajadores y sus pensiones. En primer lugar la salud de las pensiones ya no estará ligada a la de la empresa, si no al mercado de capitales (o acciones). En segundo lugar, los incentivos de los trabajadores para invertir en el capital humano específico de la compañía en la que trabajan; ha descendido. En combinación, estos dos cambios han estado ligados, no solo a una mayor movilidad laboral, sino también a un incremento de la importancia de las políticas pro-accionistas en la sociedad estadounidense. Es decir con motivo del auge de los DC Plans, las políticas proshareholders han ganado en importancia relativa, en comparación con las políticas pro empleado, que protegen su posición con un empleador determinado ${ }^{56}$. En cierta medida, la implementación de las reformas a favor de la shareholder primacy, son, en parte, la consecuencia no pensada (inintencionada) de los cambios vistos en el sistema de pensiones, y que hicieron la propuesta de la shareholder wealth maximization muy atractiva para todos los inversores en general.

Una mayoría de la opinión pública estadounidense, comparte los postulados de la Shareholder Primacy, por lo que no solo resulta más atrayente para el ciudadano en general, sino que también es más fácil de articular políticamente su defensa e implementación. Al final, tanto los accionistas no trabajadores, como los trabajadores accionistas apostaran decididamente por estas prácticas. Realmente todo ciudadano que tenga dinero invertido en el mercado de capitales (normalmente la Bolsa de valores), hará lo posible para que el valor de su inversión crezca.

Los sindicatos, por tanto, abrazaron el descubierto nuevo capitalismo de los trabajadores (también denominado «Forced Capitalism» ${ }^{57}$ ) como inversores en acciones, y empezaron a promover la «shareholder wealth maximization» como uno de sus objetivos ${ }^{58}$. Se dieron cuenta de que promoviendo las medidas a favor de los accionistas, se benefi-

55 Gelter, M.: «The Pension System and the Rise of...», op. cit., p. 945.

56 Gelter, M.: «The Pension System and the Rise of...», op. cit., p. 30.

57 STRINE, L.E.: «Toward Common Sense and Common Ground? Reflections on the Shared Interest of Managers and Labor in a More Rational System of Corporate Governance». The Journal of Corporation Law. 2007. Vol. 33, p. 4.

58 Gelter, M.: «The Pension System and the Rise of...», op. cit., p. 38. 
ciaban ellos también en su nueva cualidad, adquirida como consecuencia de los cambios legislativos antes señalados. ¿Cómo no apoyar un modelo que, precisamente, tiene como más importante divisa el beneficio de los accionistas? Por todo esto, los Unions han apoyado la legislación sobre gobierno corporativo que ha tratado de hacer al management más responsable frente a los propietarios (incluida la famosa Sarbanes Oxley Act, y todas las reforma intentadas sobre las shareholders proposals, en el sentido de dar más poder a los accionistas $)^{59}$.

Más en concreto, SCHWABS y THOMAS ${ }^{60}$, nos dan cuatro razones por las que los sindicatos de trabajadores quieren liderar el movimiento de reforma de las estructuras de Gobierno Corporativo de la Sociedad: a) Los Sindicatos tienen invertida una significativa cantidad de capital humano específico en cada una de las sociedades, por lo que son acreedores residuales de las mismas, b) Los Sindicatos tienen habilidades fiscalizadoras especiales, y pueden crear valor en favor de otros accionistas a través de su control sobre el costo de agencia del capital; c) Los Sindicatos son «extraños» al sistema de Gobierno Corporativo, y no sufren muchos de los conflictos de interés que dificultan el activismo de otros accionistas y d) Si la edad media de los miembros de los sindicatos sigue subiendo, les será muy útil centrar sus esfuerzos en incrementar la valoración de los activos que sirven de base para la el abono de las pensiones ${ }^{61}$.

\section{La nueva, e inimaginada, política de voto de los fondos de pensiones de los sindicatos en los Estados Unidos}

\section{A) Breve apunte histórico}

Los representantes de los trabajadores, a través de esta nueva actividad como Inversores Institucionales, están realizando una redefinición

59 Ibid., p. 45.

60 SchWAB, S.T. y ThomAS, R.S.: «Realigning Corporate Governance: Shareholder Activism by Labor Unions». Michigan Law Review. 1998. Vol. 96, p. 1036.

61 CIOFFI, J.W. y HöPNER, M.: «The Political Paradox of Finance Capitalism: Interest, Preferences, and Center Left Party Politics in Corporate Governance Reforms». Politics \& Society, 2006, p. 463. Estos autores, desde un punto de viasta más politico, tartan de explicar, en este artículo "...a striking political paradox of finance capitalism and corporate governance reform: center left political parties were the driving force behind corporate governance reform and the institutional adjustment to finance capitalism, while right _ of - center parties resisted reform to protect established forms of managerialism and organized capitalism». 
del tradicional rol o papel que tanto estos, como la dirección o management y los accionistas representan en las relaciones sociales. A través de las "shareholder proposals», los sindicatos aprovechan la oportunidad que tienen, también como accionistas, de hacer responsables a la dirección o management, tanto de la gestión en general de la compañía, como de las relaciones laborales en concreto. Así es, en este apartado, analizaremos, no ya la participación de los mismos en la expansión de la Shareholder Primacy (cosa que ya hemos realizado de forma sucinta en el anterior epígrafe) si no, el ejercicio concreto de su activismo accionarial, así como los posibles conflictos que tal práctica pude ocasionarles.

Tal y como veremos, con la adopción de este nuevo rol como accionistas, los Sindicatos se posicionaron, inicialmente con el movimiento que, desde los años 60, trató -y finalmente consiguió 30 años después - de desmontar la absoluta primacía del management o dirección de la empresa, en las relaciones sociales. Esta pugna, además es reflejo, de la soterrada lucha que en lo relativo a la naturaleza de las sociedades mercantiles capitalistas ha existido siempre en el ámbito académico, legal y jurisprudencial estadounidense ${ }^{62}$ y que, como bien sabemos, se encuentra actualmente claramente inclinada hacia la concepción más neo-liberal.

Si bien es cierto que el activismo63 sindical en la Juntas de las Sociedades surgió inicialmente tratando de defender la posición de los trabajadores en conflictos laborales; el mismo ha ido evolucionado hacía una forma de actuar más en sintonía con una concepción más amplia de la compañía tal y como enseguida veremos. En efecto, al haber coincidido este incremento de la participación Sindical (a través de las Shareholders Proposals), con la superación del Ilamado «managerial model» y con la llegada del Shareholder Primacy, o primacia del interés del accionista; lo que es necesario evaluar, no es sólo la utilización de la praxis accionarial como una forma de participación alternativa a la representación de los trabajadores en la empresa; si no también su im-

62 La concepción contractualista o individualista que concibe la sociedad como un mero nexo de contratos; y por otro lado la comunitarista o humanista que la entiende como un ente con responsabilidades, no solo frente a los accionistas, sino también frente a otros interesados o Stakeholders como son, los trabajadores, los acreedores, los clientes y proveedores y la comunidad en la que se ubica la sociedad.

63 YeRMACK, D.: «Shareholder Voting and Corporate...», op. cit., p. 125, en donde define el Shareholder Activism como «...efforts by investors to use their voting power as a catalyst for corporate change». 
portante intervención en el emergente equilibrio de poderes en las sociedades mercantiles post industriales ${ }^{64}$.

Como ya hemos dicho, durante la década de los 70, y coincidiendo con el despertar y la toma de conciencia de su nueva dimensión como accionistas, los fondos de los Sindicatos - de forma un tanto vehemente- utilizaron sus aún entonces escasos votos, en la defensa de sus afiliados en los conflictos laborales existentes en las sociedades en las que (vía shareholders proposals) trataban de influir. Poco a poco, y con la profesionalización de la gestión de estos fondos, tanto sus gestores como los dirigentes sindicales, fueron perfilando una estrategia más «practica». Así es, llegaron a la conclusión de que su fuerza, aunque cada vez más importante, no alcanzaba por sí sola para obtener las mayorías necesarias. Era necesario acercar sus pretensiones a las inquietudes de otros grupos de accionistas, para de este modo sumar apoyos $^{65}$. Por ello empezaron adhiriéndose a las famosas campañas de conocidos activistas, como fue el caso de Ralph Nader en la General Motors ${ }^{66}$. Estas actuaciones, buscaban más la asunción por parte de las empresas de una serie de compromisos sociales de carácter general, muy en boga en aquella época, como eran el boicot al régimen racista de Sud África, la oposición a la Guerra de Vietnam, y la lucha contra la discriminación racial67.

En los 80, los inversores en general utilizaron las propuestas, para atacar las medidas anti-Opa con las que los managers se habían dotado para blindar o atrincherarse en su posición. De forma transitoria, los representantes de los trabajadores, unieron sus fuerzas a las del management. A ellos también les interesaba la continuidad de estas medidas anti-Opa ${ }^{68}$. En efecto, los Unions Pension Funds, siempre vin-

64 Cfr. VAN DER ZWAN, N.: «The Making Of Shared Capitalism: Business, Labor and Corporate...», op. cit., p. 5.

65 SCHWAB, S.T. y ThomAS, R.S.: "Realigning Corporate Governance...», op. cit., p. 1035. Vuelven a incidir en esta idea: «Unions shareholders activity sometimes serves old union goals. But is also true that in the course of collective bargain, attempt to enlarge the overall pie as a means of getting a larger slice for workers. // But to be successful, union shareholder activism must gain the support of others shareholders. This is most likely to occur when unions embrace a goal of maximizing firm value: clearly a new way of thinking for some unions».

66 Nader, R.; Green, M. y Seligman, J.: Taming the Giant Corporation. New York. Ed: W.W. Norton \& Company Inc. 1976, p. 153. Ver en este libro, detalles de sus campañas, así como de su propuesta de «Employee Bill of Rights».

67 SchWAB, S.T. y ThomAS, R.S.: «Realigning Corporate Governance...», op. cit., p. 1044

68 Ibid..p. 1020. En donde nos dicen «In the 1980's workers often aligned with managers against shareholders in thwarting hostile takeovers, depriving shareholders 
cularon las Opas, con el cierre de empresas y por lo tanto con la pérdida de puestos de trabajo. En la década de los 90, y ya con la llegada de forma incontestada de la Shareholder Primacy, la mayoría de las propuestas accionariales presentadas, se centraron en cambiar las estructuras y funciones de los consejos, así como en tratar de limitar los salarios de consejeros y altos ejecutivos. Era necesario aprovechar de alguna forma la omnipresente corriente a favor de los accionistas imperante ya, en aquellos años. Y para ellos era necesario «plegarse» a las pautas del nuevo paradigma, concretado en la apuesta por los derechos de los accionistas, a través de la modificación de las estructuras de gobierno corporativo de las sociedades.

A día de hoy, una parte fundamental de la actividad, tanto de los gestores de los fondos sindicales, como de los responsables de los sindicatos, es el tratar de dotar a esta aparentemente contradictoria situación, de cierta homogeneidad y coherencia ${ }^{69}$ que no perjudique, ni los intereses de los accionistas, ni los de los trabajadores. Para ello, y al margen de diferentes actividades organizadas a estos efectos ${ }^{70}$, en la página web de la American Federation of Labor and Congress of Industrial Organizations ${ }^{71}$ (AFL-CIO) — que es el Sindicato más grande de los EE.UU.- , aparece instrucciones precisas sobre los criterios que este Sindicato propone utilizar cada «proxy voting season», así como el tipo

of substantial premiums in the process. In the 1990's a historic shift began, as workershareholders prod other shareholders into holding management more accountable. Increasingly Pension Funds will focus on the long run health of the Corporation...»

69 En este sentido, ver también SCHWAB, S.T. y THOMAS, R.S.: «Realigning Corporate Governance...», op. cit., p. 1040, en donde afirman "A key question in union shareholder activism is whether and how the strategies of unions and their pensions funds can and should be linked. Public pensions funds are among the fastest growing equity holders in this country. Workers are becoming capitalist».

70 Ver en JACOBY, S.: «Finance and Labor: Perspectives on Risk, Inequality and Democracy». Ver en http://www.irle.berkeley.edu/events/fall07/symposium/jacoby.pdf. Conferencia presentada en Simposium celebrado la Universidad de UCLA, Campus de Berkeley, en otoño de 2007, Última entrada 15 de enero de 2014; en su p. 26, nos dice: "A turning point came in 1997, when the AFL-CIO created an Office of Investment and a nonprofit Center for Working Capital to educate union trustees about «capital stewardship». Almost overnight, the AFL-CIO became the center of UAPF activism. It created a PayWatch website where workers could compare their earnings to those of their CEO. The site was extremely popular, getting over four million hits in its first year. According to AFL-CIO Secretary-Treasurer Rich Trumka, PayWatch offered workers a way to «vent their anger, anxiety, and outrage.» Later the website added a feature called «Pick-aPension, » which divulged CEO retirement packages and calculated how much health insurance they could buy for uncovered families.» Voting

71 Vid. AFL-CIO. http://www.aflcio.org/Corporate-Watch/Capital-Stewardship/Proxy- 
de propuestas en las que se quiere hacer énfasis en un ejercicio determinado.

Para el año 2.000 los Labors Unions habían quedado ya abducidos por la shareholder primacy, con lo que las propuestas por ellos presentadas no diferían en nada con las presentadas por cualquier otro inversor. Como nos dicen Schwabs y Thomas $^{72}$ se trataba de propuestas standars de Gobierno Corporativo, que al final lo que quieren es alinear el interés de los managers con los de los accionistas. Dos son pues las razones que han movido a los Sindicatos a plegarse a las nuevas exigencias: a) Muchos Pension Funds han concluido que las reformas de gobierno corporativo realmente aumentan el valor de la inversión, y b) Las propuestas realizadas por los Unions Pension Funds en este sentido, son las que obtienen un mayor apoyo de otros accionistas ${ }^{73}$.

Cómo ejemplo del contenido de este nuevo activismo sindical, podemos señalar los datos publicados en post ${ }^{74}$ colgado el 21 de Marzo de 2013 en el blog «The Harvard Law School Forum on Corporate Governance and Financial Regulation»; resaltando como más llamativos, a los efectos de la materia que nos ocupa, los siguientes: Que las propuestas realizadas, de forma general, coinciden, en cuanto al tema o materia, con las presentadas el año anterior. Existiendo una preferencia de los Public Pension Funds por los temas relacionados con el sistema de elección de consejeros y las mayorías exigidas a tal efecto. Mientras que las presentadas por pequeños accionistas, hacen referencia más a la remuneración de los directivos y consejeros y a la recomendación de que no coincida en la misma persona el cargo de Presidente del Consejo y el de CEO. En concreto se hace referencia a las presentadas por el sindicato United Brotherhood of Carpenters $(\mathrm{UBC})^{75}$ relativas a salarios y otras formas de compensación de altos directivos, y la de CALSTRS ${ }^{76}$ anunciando medidas contra las compañías que no atendiesen las propuestas realizadas y que hubieran obtenido una mayoría de votos.

De igual manera otros fondos de pensiones públicos, fondos «éticos» (o que invierten exclusivamente en compañías socialmente res-

72 SchwaB, S.T. y Thomas, R.S.: «Realigning Corporate Governance...», op. cit., p. 1045

73 Ibid., pp. 1085 y 1086

$74 \mathrm{Vid}$ en http://blogs.law.harvard.edu/corpgov/2013/03/21/2013-proxy-seasonpreview-key-shareholder-proposals/. p. 1. Última entrada 10 de enero de 2014.

75 Ibid., p. 3.

76 Vid. En la página web. del fondo que reúne los planes de pensiones de los profesores del Estado de California (California Teachers Retirement System) http://www. calstrs.com/people-calstrs. Última entrada 11 de enero de 2014. 
ponsables), así como los vinculados con diversas asociaciones religiosas, se han unido para promover la diversidad de género en los consejos de administración, aunque específicamente han dicho que no quieren un sistema de cuotas. Finalmente ${ }^{77}$ se mencionan las nuevas propuestas relacionadas con las retribuciones que están siendo presentadas por distintos Unions Pension Funds. La primera es la esponsorizada por la Utility Workers Unios of America, que solicita a las compañías que no utilicen como criterio para establecer el sueldo del CEO su comparación con el de otros iguales (ya que está demostrado que esta técnica es la causante de una espiral de subidas que no tiene fundamento). La otra es la promovida por el sindicato AFL-CIO, relativa a las explicaciones dadas por las compañías en relación con los sueldos de sus altos directivos (Say on Pay), cuando no alcanzan un \% de votos determinados.

No obstante, no parece «natural» que los sindicatos, cuya finalidad es representar los intereses de los trabajadores; hagan suya una forma de entender la sociedad que tiene sus orígenes intelectuales en la escuela económica del derecho, y en la corriente legal contractualista de signo descaradamente neo-liberal. En efecto, parece que hubiera sido más coherente una defensa más activa, decidida, de las posiciones comunitaristas y progresivas que predican una visión más humanista de la sociedad, o por decirlo de otra forma, que propugnan tener en consideración los intereses de otros «constituencies» distintos a los accionistas. La doctrina señala ${ }^{78}$ como causa de esta "metamorfosis», tanto la dramática pérdida de afiliación, y por lo tanto de fuerza, de estas organizaciones desde los años 80; así como el envejecimiento paulatino de sus bases, lo que conlleva la existencia de más pensionistas (o miembros pasivos) que activos ${ }^{79}$. Consecuentemente, obtener una buena rentabilidad a sus inversiones, para atender las pensiones de sus mayores, devino relativamente más importante que cualquier otra consideración. Citando a Gelter ${ }^{80}$, podemos decir que tal y como una vez un profesor manifestó en una conferencia «The closer I get to retirement the more I like shareholder wealth maximization».

77 Vid.en http://blogs.law.harvard.edu/corpgov/2013/03/21/2013-proxy-seasonpreview-key-shareholder-proposals/. p. 6. Última entrada 10 de enero de 2014.

${ }^{78}$ GeLTER, M.: "The Pension System and the Rise of...», op. cit., p. 35,

79 Confirman esta argumentación SCHWAB, S.T. y THOMAS, R.S.: «Realigning Corporate Governance...», op. cit., p. 1039, en donde dicen "We tentatively suggest that increasing levels of union shareholder activism may be due in part to a shift in the age composition of the unions. If the age distribution of labor unions is getting older, as statistical evidence suggest it is, unions likely will place increased emphasis on retirement conditions, employer contributions, and other pension-related matters». 
En efecto, una parte importante de la doctrina, demandó una reactivación del tradicional y combativo espíritu sindical, para adecuarlo a las necesidades y configuración de la nueva sociedad post-industrial. Es el caso de Roth ${ }^{81}$, quién dando como bueno el principio del incremento del valor del accionista, añade la variable — trascendental- del largo plazo. Para ello propone la aplicación del «enlightened shareholder value» ${ }^{82}$ cómo teoría que puede superar este paradigma o dicotomía. Esta idea nivela el clásico conflicto entre la Shareholder Primacy y el Stakeholder model.

Pero más recientemente y, como consecuencia de todo ello, los sindicatos han ido expandiendo o ampliando de forma voluntaria sus obligaciones, más allá de la responsabilidad hacia los trabajadores o los accionistas, para incluir, entre sus prioridades, el bien común de la comunidad en la que una compañía está situada o ubicada. En definitiva, se implementó la política de tratar de hacer responsable a la empresa frente a los stakeholders ${ }^{83}$. Eliminaron cualquier conexión entre el gobierno corporativo y las propuestas vinculadas con los derechos de los empleados. ${ }^{84}$ Así que los sindicatos poco a poco, no solo se presentaron como representantes de trabajadores titulares de capital social, si no como «verdaderos» accionistas ${ }^{85}$, cuyas preocupaciones financieras eran exactamente las mismas que las de cualquier otro inversor ${ }^{86}$.

81 Roth, M.: «Labor and Comparative Corporate Governance...», op. cit., p. 784.

82 Vid. KEAY, A.: The Enlightened Shareholder Value Principle and Corporate Governance. New York. Ed. Routledge. 2013. En este sentido, este autor nos dice que «Enlightened Shareholder Value may be regarded as making a slight change to the shareholder value theory as it involves directors not only having to act in the collective best interest of shareholders, but it demands an approach that values the building of long term relationships».

83 Cfr. VAN DER ZWAN, N.: "The Making Of Shared Capitalism: Business, Labor and Corporate...», op. cit., p. 32.

84 Ibid., p. 33.

85 En palabra de SCHWAB, S.T. y THOMAS, R.S.: «Realigning Corporate Governance...», op. cit., p. 1019. "Labor Unions are active again: but this time as capitalists».

86 Vid. JACOBY, S.: «Finance and Labor: Perspectives on Risk, Inequality...», op. cit., en su página 20, afirma: «lt's important to represent workers as stockholders as well as workplace advocates ... so employees are engaging companies with their view of shareholder value.» What came to be called the «worker-owner» or "capital stewardship» philosophy had four objectives. First was a search for investments that would protect workers while meeting fiduciary guidelines. Second was advocacy of mainstream governance principles that would give labor common ground with other institutional investors. By calling for shareholder rights, labor acquired a more positive public image while at the same time tarnishing management's. Third, UAPFs sought to persuade other investors that worker objectives were positively associated with long-term value. Finally, there was the hope that exercising shareholder power would give labor influence at the corporation's highest levels, a goal that had eluded it since the 1970s». 
En resumen los sindicatos (sus fondos) han quedado subsumidos por la economía política imperante en los Estados Unidos, adoptando la lógica de la Shareholder Primacy, que inicialmente combatieron. Aunque al principio la utilizaron solo como medio para contrarrestar el poder del management, finalmente han sucumbido a su practicidad e innegable atractivo. No obstante, han tratado de "dulcificar» la misma, realizando una apuesta por el largo plazo, así como por la toma en consideración -en sus propuestas - del principio de que el incremento del valor para el accionista debería ser creado (solo) si la compañía también promueve el interés de los empleados, clientes, proveedores, y la ciudadanía en general. Y si bien es cierto que este principio o desideratum, podría ser más fácilmente conseguido si se elige un diseño que promueva una visión distinta de la sociedad mercantil capitalista (dando, por ejemplo, voz al capital humano en el gobierno corporativo de las sociedades) lo cierto es que aún se está muy lejos de tal escenario ${ }^{87}$.

\section{B) Oposición a la misma}

Pero obviamente esta nueva actividad, no quedo incontestada por el management. Así es, desde los años 70, se opusieron a este nuevo activismo, en base a dos argumentos distintos: a) La actuación sindical violentaba la libertad de gestión que la dirección de la sociedad ha de tener y b) Se cuestiono la legitimidad de los sindicatos a aparecer como accionistas en las Juntas. En realidad —argumentaban los managerseste nuevo papel de accionistas era un mero disfraz que trataba de ocultar o encubrir una motivación exclusivamente laboral ${ }^{88}$. Los sindicatos, al presentar su actuación como un terreno de juego común, entre los trabajadores como empleados y los trabajadores como accionistas; trataron de hacer compatible su representación en el consejo con su rol en el proceso de negociación colectiva ${ }^{89}$.

87 Posibilidad, que formalmente ya existe en muchos estados pero que no se utiliza, tal y como ya expusimos en nuestro trabajo, publicado en esta misma revista ZAVALA ORTIZ DE LA TORRE, I.: "La pugna el shareholder primacy model y la stakeholder theory en la doctrina y práctica anglosajona. Estado de la cuestión». Deusto Estudios Cooperativos. 2013. Vol. 2, pp. 103 y ss.

88 JACOBY, S.: «Finance and Labor: Perspectives on Risk, Inequality...», op. cit., p. 12.

89 Cosa que nunca se ha conseguido, ver a este respecto, O'CONNOR, M.: "Labor's Role in the American Corporate Governance Structure». Comparative Labor \& Policy Journal. 2000. Vol. 22, p. 97. 
En el terreno práctico, la táctica utilizada por las empresas para evitar o limitar la acción de los Unions Pension Funds, fue la de invocar alguna de las 13 prohibiciones contenidas en la Rule 14a-8, y que permitían - recordamos - excluir la propuesta realizada del orden del día de la Junta. En concreto nos referimos a las señaladas con las letras d) «Personal Grievance Exclusion» y sobre todo la g) «Ordinary Business Exclusion ${ }^{90}$ (Las que hacen referencia a una reclamación personal contra la sociedad o un directivo y las que hacen referencia al día a día de los negocios sociales). Centrándonos, en las segundas que son las que realmente han dado más juego a lo largo de la azarosa historia de esta norma, podemos decir que la posición de la SEC ha variado a lo largo de los años. Con anterioridad a 1992 la Comisión interpreto la norma — sorprendentemente- en el sentido que cuando la shareholder proposal perseguía finalidades sociales, esta Ordinary Business Exclusion, no podía ser invocada, por lo que las propuestas podían ser incorporadas al orden del día. Pero en 1992, la SEC modifico esta interpretación en el asunto "Cracker Barrel Old Country Store, Inc.»"1 permitiendo a la compañía excluir la propuesta (se trataba de una petición que solicitaba a la compañía el suprimir una serie de criterios que según los proponentes discriminaban a los empleados según su orientación sexual), aunque la misma, obviamente también suscitaba cuestiones sociales. Si bien los proponentes recurrieron la decisión de la Comisión y ganaron en primera Instancia, la apelación ante el Segundo Circuito volvió a confirmar la decisión de la SEC ${ }^{92}$. En 1997 volvió a modificar este criterio en una disputa por una propuesta realizada por el Sindicato de Camioneros, al fabricante de tabaco Philip Morris, en el sentido de solicitar la creación de un comité, que determinara las compensaciones de los altos ejecutivos, en el seno del consejo.

Realmente a día de hoy, ya se han normalizado este tipo de propuestas, y no hay problema en admitir todas aquellas, que no supongan una intromisión directa en la gestión de los negocios sociales que - al igual que en el resto del mundo- es una facultad reservada a la dirección de la sociedad.

90 SchWAB, S.T. y Thomas, R.S.: "Realigning Corporate Governance...», op. cit., p. 1050.

91 Ibid., p. 1051.

92 Ver New York City Employees'Retirement System v. SEC, 843 F. Supp.858 (S.D.N.Y. 1994), revd, 45 F 3d 7 (2d Cir. 1995) en SCHWAB, S.T. y THOMAS, R.S.: «Realigning Corporate Governance...», op. cit., p. 1051. 


\section{C) Potencial Conflicto de Intereses}

Es claro que los Fondos de los Sindicatos de Trabajadores, a menudo, pueden incurrir en un potencial conflicto de intereses. En efecto, cuando actúan como accionistas, pueden estar tentados de tratar de incrementar el valor de la sociedad, con el propósito de maximizar el valor de sus acciones. Mientras que cuando actúan como representantes de los trabajadores, podrían sacrificar el valor de la sociedad en su conjunto, con el objetivo de proteger el trabajo de sus afiliados o simpatizantes.

Este peligro, que es lógico, en tanto en cuanto que ninguna actividad humana admite con facilidad la defensa de intereses contrapuestos, se ve atemperado por una serie de mecanismos que, la doctrina a señalado como limitadores de estos potenciales conflictos.

Estos son los siguientes:

a) El deber de lealtad impuesto a los administradores de fondos, por la Taft-Hartley Act ${ }^{93}$ y la ERISA

La cuestión es hasta qué punto los Union Pension Funds tienen limitado el uso de su derecho de voto para perseguir un fin distinto al de maximizar su inversión ${ }^{94}$. Es decir, incrementar el valor de la compañía, y con él, el de la acción. En efecto la Taft-Hartley específicamente trataba de que los sindicatos no usaran estos fondos como un «war chest» ${ }^{95}$.

Aunque la administración de estos Fondos estaba pensada de forma paritaria, la verdad es que los sindicatos han tendido a controlarlos. La razón es que al ser la mayoría de estos Fondos, defined-contributions plans, el empleador cumple simplemente con realizar la aportación pactada anualmente al fondo. Una buena gestión del mismo es lo que hará que sus beneficiarios obtengan superiores retribuciones, tal y como ya hemos comentado.

La Taft-Hartley Act imponía a los administradores del plan, la obligación de gestionar el mismo en el «solo y exclusivo beneficio de los empleados...y sus familias y personas dependientes» e insistiendo en que «...los fondos gestionados, no podrán ser utilizados para otro pro-

93 Ver en la U.S. Goverment Printing Office.El nombre técnico de la Ley es la Labor Management Relations Act of 1947. Aunque desde 1994, paso a ser parte del U.S.C.. ver en http://www.gpo.gov/fdsys/granule/USCODE-2011-title29/USCODE-2011-title29chap7-subchaplV-sec186/content-detail.html. Última entrada 15 de enero de 2014.

94 SCHWAB, S.T. y THOMAS, R.S.: «Realigning Corporate Governance...», op. cit., p. 1076.

95 Ibid., p. 1077. 
pósito distinto al de pagar las pensiones o anualidades» ${ }^{96}$. Es decir, la ley ha limitado de forma clara y contundente, a favor de quien sí y de quién no, deben estos fondos estar gestionados. En ningún caso permite la ley realizar inversiones que tengan una finalidad política o social que, al margen de su legitimidad, puedan poner en peligro la inversión y con ello comprometer los ahorros de los trabajadores que les encomiendan los mismos.

Pero ha sido la Employee Retirement Income Security Act de 1974 (ERISA) ${ }^{97}$, la que ha impuesto mayores deberes a los gestores de de Fondos de Pensiones Privados, sean estos gestionados, por las compañías, o por estas y los sindicatos. En efecto, además de exigir la diligencia de un ordenado empresario y un representante leal (prudent person standart), hace a los administradores, individualmente responsables, ante cualquier incumplimiento del deber de lealtad para con los beneficiarios del plan o fondo.

El resultado ha sido que los Unions Pensions Funds, han reaccionado de distintas formas, ante las tensiones surgidas como consecuencia de haber devenido importantes inversores en el mercado de capitales. Algunos de ellos han evitado el mercado de acciones, invirtiendo exclusivamente en renta fija; por lo que no tendrán que ejercitar en ningún caso el derecho de voto. Otros no invierten en compañías que no cuenten con representantes sindicales (cuestión esta bastante común en los EE.UU); o incluso deciden ligar el sentido de su voto, a la opinión de un asesor externo, o Proxy Advisor ${ }^{98}$, de tan rabiosa actualidad en el inicio de este siglo XXI.

De hecho una parte central de la regulación de la ERISA sobre los Union Pension Funds, regula las denominadas inversiones sociales del sindicato. Es el caso de inversiones que se realizan en compañías que, por ejemplo, tienen como objeto social, la concesión de préstamos para la compra de viviendas a trabajadores; o empresas de construcción que emplean a trabajadores sindicados. Esta práctica ha dado lugar a mucho debate y litigios, originados por la idoneidad y seguridad de tales inversiones, en el marco de la finalidad general de lo que es un fondo y

96 Ver de nuevo en http://www.law.cornell.edu/uscode/text/29/186. Última entrada 7 de enero de 2014.

97 Ver en la página web del Departament of Labor (DOL). http://www.dol.gov/dold topic/health-plans/erisa.htm. Última entrada 7 de enero de 2014.

98 Vid. La página web de Institutional Shareholder Services, que es el Proxy Advisor más grande del planeta en http://www.issgovernance.com, última entrada 12 de enero de 2014. Esta compañía, se jacta de asesorar el voto en más de 40.000 Juntas Generales de accionistas al año. No acabamos de comprender como es esto posible. 
un plan de pensiones. Aunque no podemos entrar en el análisis de esta interminable casuística, si que podemos mencionar que, como criterio general el Ministerio de Trabajo (o Department of Labor) ha sugerido que los fondos podrán realizar inversiones que beneficien a los sindicatos o a sus trabajadores, siempre que la relación entre el riesgo de la inversión y su retorno, se sitúe en la media de riesgo atribuido a otras de similares características ${ }^{99}$. Es decir la ERISA permite a los fondos de pensiones de los sindicatos a invertir en proyectos que benefician a los trabajadores, en tanto que el riesgo y el retorno o beneficio sea igual al de otros proyectos ${ }^{100}$.

Incluso la ERISA, indirectamente, impone algunos límites en lo relativo al uso que de las Shareholders Proposals, pueden realizar estos fondos. Así es, solo aquellas que justifiquen los costos incurridos en resoluciones relativas a Gobierno Corporativo, estarían permitidas. Por lo tanto los Unions Pension Funds, arriesgarían una acción judicial, al amparo de la mencionada Ley, cuando sufraguen resoluciones que claramente producen magros retornos. Es decir, los administradores del mismo, podrían tener que responder ante los participes del fondo, por un incumplimiento del deber de lealtad, concretado en un gasto sin un retorno proporcionado.

b) Estos fondos necesitan el apoyo de otros accionistas, para que sus iniciativas tengan éxito ${ }^{101}$

La mayoría de las iniciativas realizadas por los sindicatos de trabajadores, no tendrán éxito, si no reciben el apoyo de otros accionistas. Necesitan apoyo, incluso para aquellas que tan solo implican una recomendación, como es el caso de la Rule 14a-8. Otros accionistas tendrán una mejor disposición a votar a favor de las que proponen estos fondos sindicales, cuando las mismas impliquen la posibilidad de mejorar el Gobierno Corporativo de la sociedad. Por el contrario cuando estos Union Funds, se centran en materias que afectan más directamente a intereses de los trabajadores, reciben mucho menos apoyo.

Esto no es ninguna sorpresa. Los Fondos Sindicales van a tener que realizar un esfuerzo mucho mayor, por tratar de convencer a accionistas racionales, cuando de la propuesta no se desprenda claramente que la misma va a redundar en provecho de todos ellos. Muchos accionistas son escépticos ante propuestas que parecen tener un objetivo

99 SchWAB, S.T. y Thomas, R.S.: «Realigning Corporate Governance...», op. cit., p. 1078.

100 Ibid., p. 1081.

101 Ibid., p. 1082. 
pro-trabajador demasiado evidente. Son entendidas como injustificadas incursiones, en beneficio de un determinado grupo de interés. Si quieren construir coaliciones con otros accionistas, tienen que ser capaces de darles algo a cambio ${ }^{102}$.

Pero la doctrina, no solo de forma unánime secunda la estrategia de que los Unions Funds establezcan coaliciones o acuerdos tácitos o expresos con otros accionistas (principalmente, otros inversores institucionales), sino que incluso, recomienda retomar la alianza con el management de la compañía que ya se dio en la década de los 80. Así es, para algunos autores, el actual apoyo de los Fondos Sindicales a la Shareholder Primacy, es contra-natura. La coalición natural ha de ser con la dirección, para resistir a las omnipresentes y succionadoras políticas de beneficios, en interés exclusivamente de los accionistas ${ }^{103}$.

c) La disciplina del mercado

Las fuerzas del mercado, actúan como un control final ante formas exageradas de oportunismo sindical. El mercado nunca permitiría que una empresa atendiera demandas disparatadas de los representantes de los trabajadores. Ni el mercado de crédito, ni el de acciones, ni siquiera el propio mercado laboral permanecería impasible ante cualquier acción que afectase a la viabilidad de la empresa ${ }^{104}$.

\section{Conclusiones}

Debido a la profunda crisis representativa y económica, sufrida por los sindicatos en los Estados Unidos; han tenido que reposicionarse en el actual sistema de relaciones sociales de la sociedad post-industrial.

Como consecuencia, además, de un cambio en el sistema de pensiones de aquél país, el éxito o fracaso de los planes y fondos de pensiones sindicales está mucho más vinculado a la situación del mercado de capitales, que a la marcha de las empresas.

La actividad sindical, a través de las shareholder proposals es igual a la de cualquier otro Inversor Institucional, ante la necesidad de aquellos de buscar aliados para sacar adelante sus propuestas.

102 Ibid.p. 1083.

103 Vid. StRINE, L.E.: «Toward Common Sense and...», op. cit., p. 1. En este renombrado artículo el Presidente Juez Tribunal Supremo de Delaware (nombrado el 8 de enero de 2014), aboga por esta política de alianzas.

104 SChWAB, S.T. y Thomas, R.S.: «Realigning Corporate Governance...», op. cit., p. 1081 
Los Sindicatos, que una vez fueron los oponentes, tanto del management como de los accionistas, en el aseguramiento de mejores condiciones de trabajo para los trabajadores, han sido cooptados al capitalismo accionarial, a través del sistema de pensiones.

La brecha entre la Shareholder Primacy y la Stakeholder model (hasta ahora claramente ganada por la primera) puede ser superada si utilizamos como puente, entre ambos conceptos, el largo plazo como un principio dominante o global de gobierno Corporativo en estos tiempos de "Pension Capitalism». Reflejando su interés en el crecimiento a largo plazo del valor de la sociedad, y en la defensa de los intereses de todos los stakeholders, los Union Pension Funds, deben de ser, de nuevo, instituciones que luchen por el crecimiento sostenible de las compañías.

\section{Bibliografía}

Libros

Blodgett, R.: «Union Pension Fund Asset Management», en Abuse on Wall Street: Conflicts of Interest on the Securities Markets. New York. Ed: Preager.1980.

Bogle, J.C.: The Class of the Cultures. Investment v. speculation. Hoboken. New Jersey. Ed: John Wiley \& Sons Inc. 2012.

Cox, J.D.; Hillman, R.W. y LAgenvoort, D.C.: Securities Regulation. Selected Statutes, Rules and Forms. Frederick. Maryland. Ed:Wolters Kluwer. 2012.

Davis, R.B.: Democratizing Pension Funds. Toronto. Ed: Ubc Press. 2008.

DRUCKER, P.F.: The Unseen Revolution: How Pension Fund socialism came to America. New York. Ed: HarperCollins. 1976.

GevurTz, F.A.: Corporation Law. Second Edition. Minnesota. Ed: Thompson Reuters. 2010.

KEAY, A.: The Enlightened Shareholder Value Principle and Corporate Governance. New York. Ed. Routledge. 2013.

Nader, R.; Green, M. y Seligman, J.: Taming the Giant Corporation. New York. Ed: W.W. Norton \& Company Inc. 1976.

Seligman, J.: The transformation of Wall Street. 3. ${ }^{a}$ edición. New York. Ed: Aspen Publishers. 2003.

\section{Revistas}

AnabtaWI, I. y Stout, L.: «Fiduciary Duties for Activist Shareholders». Stanford Law Review. 2007. Vol. 60. 
AsHRAF, R. et al.: "Conflicts of interest and mutual fund proxy voting: Evidence from shareholder proposals on executive compensation». Journal of Financial and Quantitative Analysis. 2012. Vol. 47. Issue 3.

BAINBRIDGE, S.: «The Case for Limited Shareholders Voting Rights». UCLA Law Review. Vol. 53.

Brav, A. et al.: "Hedge Fund Activism, Corporate Governance and Firm Performance». The Journal of Finance. 2008. Vol. 63, n. ${ }^{\circ} 4$.

CAMARA, K.A.D.: "Classifying Institutional Investors». The Journal of Corporation Law. 2005. Winter.

CIOFFI, J.W. y HöPNER,M.: «The Political Paradox of Finance Capitalism: Interest, Preferences, and Center Left Party Politics in Corporate Governance Reforms». Politics \& Society. 2006.

FaleYe, O.; Mehrotra, V. y MorCK, R.: «When labor has a Voice in Corporate Governance». Journal of Financial and Quantitative Analysis. 2006. Vol. 41. Issue 3.

FogdalL, S.: «Exclusive Union Control of Pension Funds: Taft - Hartley's III Considered Prohibition». University of Pennsy/vania Journal of Labor and Employment Law. 2001. Vol. 4.

Gelter, M.: "The Pension System and the Rise of Shareholder Primacy». Seton Hall Law Review. 2013. Vol. 43, n. ${ }^{\circ} 3$.

GHILARDUCCI, T.; HAWLEY, J. y WilLIAMS, A.: «Labour Paradoxical Interest and the Evolution of Corporate Governance». Journal of Law and Society. 1997. Vol. 24.

KAHAN, M. y Rock, E.B.: «Hedge Funds in Corporate Governance and Corporate Control». University of Pennsylvania Law Review. 2007. Vol 155, n. ${ }^{\circ} 5$.

LARCKER, D.F. y TAYAN, B.: «Union Activism: Do Union Pension Funds Act Solely in the Interest of Beneficiaries? Stanford Closer Look Series. 11 de diciembre de 2012.

O'ConNoR, M.A.: «Organized Labor as Shareholder Activist: Building Coalitions to Promote Workers Capitalism». University of Richmond Law Review. 1997. Vol. 31.

RenNeBoog, L. y SzILAGVI, P.G.: «The Role of Shareholders Proposals in Corporate Governance». Journal of Corporate Finance. 2010. Vol.17.

Romano, R.: «Public Pension Fund Activism in Corporate Governance Reconsidered». Columbia Law Review. 1993. Vol. 93.

Rотн, M.: «Labor and Comparative Corporate Governance in Times of Pension Capitalism». Fordham Journal of Corporate \& Financial Law. 2013. Vol. XVIII.

StRINE, L.E.: «Toward Common Sense and Common Ground? Reflections on the Shared Interest of Managers and Labor in a More Rational System of Corporate Governance». The Journal of Corporation Law. 2007. Vol. 33.

THOMAS, R.S. y MARTIN, K.J.: "Should Labor be allowed to Make Shareholders Proposals». Washington Law Review. 1998. Vol. 73, n. ${ }^{\circ} 1$.

Tusk, D.: "Shareholders as Proxies: The Contours of Shareholder Democracy». Washington \& Lee Law Review. Vol. 63. 2006.

YeRMACK, D.: "Shareholder Voting and Corporate Governance». Annual Review of Financial Economics. 2010. Vol. 2. 
Zelinsky, E.A.: «The Defined Contribution Paradigm». Yale Law Journal. 2004. Vol. 114.

\section{Páginas Web}

AFL-CIO. http://www.aflcio.org/Corporate-Watch/Capital-Stewardship/ProxyVoting.

CALPERS (California Public Employees Retirement System) http://www.calpers. ca.gov,

CALSTRS (California Teachers Retirement System) http://www.calstrs.com people-calstrs

CORNELL UNIVERSITY. http://www.law.cornell.edu/uscode/text/29/186

DEPARTAMENT OF LABOR. Employees Benefits Security Administration. http://www. dol.gov/ebsa/pdf/1975-2006historicaltables.pdf.

FORBES MAGAZINE. http://www.forbes.com/sites/nathanvardi/2013/12/04/carlicahn-is-wall-streets-person-of-the-year-and-going-after-apple/.

GIBSON DUNN http://www.gibsondunn.com/publications/pages/ShareholderProposal-Developments-2013-Proxy-Season.aspx.

HarVard LAW SChOOl Forum on Corporate Governance and Financial Regulation http://blogs.law.harvard.edu/corpgov/2013/03/21/2013-proxy-season-preview-key-shareholder-proposals/.

INSTITUTIONAL SHAREHOLDER SERVICES, en http://www.issgovernance.com

JACOBY, S.: "Finance and Labor: Perspectives on Risk, Inequality and Democracy». Ver en http://www.irle.berkeley.edu/events/fall07/symposium acoby.pdf. Conferencia presentada en Simposium celebrado la Universidad de UCLA, Campus de Berkeley, en otoño de 2007.

NATIONAL LABOR RELATIONS BOARD http://www.nlrb.gov/resources/national-laborrelations-act

NeW YoRK UnIVERSITY. Agrawal, A.K.: "Corporate Governance Objectives of Labor Union Shareholders: Evidence from proxy Voting». http://archive.nyu. edu/bitstream/2451/27848/2/wpa08006.pdf.

SECURITIES EXCHANGE COMMISSION. [http://WwW. conference-board.org/publications/ publicationdetail.cfm?publicationid=1872.

Social Science Research NetWork. Prevost, A.K.; Rao, R.P. y Williams, M.A.: "Shareholder Activist: Champions or Detractors», en http://papers.ssrn. com/sol3/papers.cfm?abstract_id=1119328

VAN DER ZWAN, N.: «The Making of Shared Capitalism: Business, Labor and Corporate Accountability in the Late Twenty Century». Paper presentado en el Workshop for the Study of Employee Ownership, Profit-sharing and BroadBased Stock Options; Rutgers University, New Brunswick, New Jersey, 24 y 25 de febrero de 2011. Ver en el enlace http://smlr.rutgers.edu/2011making-of-shared-capitalism-business-labor-and-corporate-accountabilitynatascha-van-der-zwan.

VANGUARD FUNDS. https://investor.vanguard.com/corporate-portal 